\title{
Fragmenting forests: the double edge of effective forest monitoring
}

\author{
Andrew R. Bell ${ }^{a, *}$, Rick L. Riolo ${ }^{b}$, Jacqueline M. Doremus ${ }^{a}$, Daniel G. Brown ${ }^{a}$, \\ Thomas P. Lyon ${ }^{a}$, John Vandermeer ${ }^{a}$, Arun Agrawal ${ }^{a}$ \\ a School of Natural Resources and Environment, University of Michigan, Ann Arbor 48109, USA \\ ${ }^{\mathrm{b}}$ Center for the Study of Complex Systems, University of Michigan, Ann Arbor 48109, USA
}

Keywords:

Agent-based model

Concession forestry

Congo Basin

Monitoring

REDD+

\begin{abstract}
A B S T R A C T
The link between ineffective forest monitoring and forest degradation is well known. Under REDD+, monitoring stands to become more important as a means of maintaining incentive. Little attention however has been paid to the possible adverse consequences of forest monitoring. Our research develops a spatially explicit, agent-based model (ABM) of timber extraction in a Congo Basin forest concession to investigate the potential conservation impact of more effective monitoring. We modeled the building of access roads, and logging of legal timber and illegal timber, where illegal timber may be interpreted broadly to include prohibited species, smaller trees, or trees in areas where cutting is not permitted. We investigated road building under (1) random spot monitoring of logging sites and (2) monitoring of logged trunks at checkpoints. Our findings indicate that although more effective monitoring can reduce illegal harvesting, it can also lead to construction of denser road networks and higher levels of forest fragmentation, with an implied loss of biodiversity. These insights are particularly relevant in the context of REDD+, as they suggest that some monitoring strategies may lead to more forest fragmentation, even as they help reduce emissions.
\end{abstract}

\section{Introduction}

Where conservation and environmental outcomes are concerned, monitoring is essential. A consistent body of research shows that poor monitoring and enforcement lead to negative conservation consequences such as habitat degradation and loss of biodiversity (e.g., Barrett et al., 2001), and effective monitoring helps overcome problems of illegal harvesting and resulting adverse environmental outcomes (Chhatre and Agrawal, 2008; Gibson et al., 2005). Relatively few scholars see more effective monitoring as producing negative consequences; those who do mostly cite greater costs associated with more comprehensive or careful monitoring that may not yield commensurate benefits in terms of reduced illegal or undesirable activities. Under the proposed activities of regimes such as REDD+ (Reducing Emissions from Deforestation and Forest Degradation) (Agrawal et al., 2011; Phelps et al., 2010; Stickler et al., 2009), monitoring and enforcement will be critical in establishing incentives for landholders and reducing risks for investors. Understanding the link between forest monitoring and land cover outcomes is thus of importance.

Our research adds a new dimension to the existing work on resource governance by incorporating a spatial component to the analysis of monitoring. Using an agent-based model (ABM), we investigated how more effective monitoring may influence conservation outcomes in logging concessions in tropical forests. Our results suggest that incorporating the spatial features of monitoring and resources is important to better understand the relationship between improved monitoring and

\footnotetext{
* Corresponding author.

E-mail address: ab3477@columbia.edu (A.R. Bell).
} 
its impacts on conservation. In particular, our analysis suggests that depending on the spatial distribution of resources being protected, more effective monitoring might undercut one of the key goals of improved governance of logging concessions: conservation of biodiversity.

Results from our ABM of monitoring indicate that although more effective monitoring can reduce illegal forest harvesting, it can simultaneously lead to higher levels of forest fragmentation, with an implied loss of biodiversity. The link is that effective monitoring and enforcement causes logging companies to harvest only legal timber, thereby driving them to harvest less intensively in any given location and instead build a more extensive road network that allows them to harvest over a wider area. Recent accelerated growth of road networks in the Congo Basin has been documented (Laporte et al., 2007); the impacts of these road networks on forest structure and access can adversely affect biodiversity even as monitoring reduces illegal harvesting, net levels of timber extraction, and terrestrial emissions.

In our study, we modeled the building of access roads, and logging in forest concessions of two classes of tree: legal timber and illegal timber, where the model allows illegal timber to be interpreted broadly to include prohibited species, smaller trees, or trees in areas where cutting is not permitted. We investigated road building under two types of monitoring and enforcement-(1) random spot monitoring of logging sites and (2) monitoring of logged trunks at checkpoints - in order to make a link between levels of monitoring effectiveness and outcomes for both the forest and concession-holder. Our results show that under both approaches, a greater expected penalty leads concession holders to refrain from cutting illegal timber and instead to build more extensive access roads to cut legal timber. Higher forest fragmentation (measured as lower average distances of forest grid cells to roads for a given total harvest) is consistently observed across forests with varying densities of legal timber when effective monitoring is present.

\section{Background}

The Congo Basin holds the world's second largest contiguous tropical rainforest, and the largest in Africa. Forestry in the Congo Basin is similar to arrangements in tropical rainforests elsewhere, with most land being cut under large-scale (>100,000 ha) concessions (Mertens et al., 2001), along with other arrangements for felling of trees at smaller scales ( 2500 ha in the Cameroon case). Of the five ITTO-member countries in the Congo Basin, industrial concession forestry is most active in Gabon, Cameroon, and Republic of Congo (ROC), with dwindling forest resources in the Central African Republic (CAR) and as-yet undeveloped potential in the Democratic Republic of Congo (DRC) (Pérez et al., 2005). Congo Basin forestry is highly selective with the focus of timber operators being on only a few species, and only a few trees felled per hectare (Pérez et al., 2005; Zhang et al., 2006). This means that the direct impact of forestry is more degradation than deforestation (Zhang et al., 2006). The handful of species that dominate production include Okoumé (Aucoumea klaineana) in Gabon and the coast of ROC; Sapelli (Entandrophragma cylindricum) and Sipo (Entandrophragma utile) in the interior of ROC, CAR, and parts of Cameroon; Ayous (Triphlochiton scleroxylon), Iroko (Milicia excelsa and Chlorophora excelsa), and Azobé (Lophira alata) in DRC and much of Cameroon (Pérez et al., 2005).

Although the term 'concession' has a broad interpretation in the literature (Hardin, 2011), here we follow Karsenty et al. (2008) and use it to refer specifically to industrial forestry operations. In the Congo Basin context, 'industrial' has also come to mean 'foreign'; while many national logging companies exist in Cameroon for example (with the number rising), foreign industrial logging operations still account for five times more felled trees by volume than these Cameroonian enterprises (Brown and Ekoko, 2001). In some ways, foreign and national logging companies occupy different niches in the industry. For example, foreign groups are more able to cope with regulations and costs of larger concessions, while national groups are better positioned to exploit local markets and work with local governments (Pérez et al., 2006). Concessions in the basin are typically on the order of the length of a single harvest rotation (25-30 years), with cutting authorized annually and the contract subject to cancellation, helping in theory to reduce 'hit-and-run' plundering of forest resources (Karsenty et al., 2008). However, this requires commitment from governments to monitor and enforce regulations (Karsenty et al., 2008), and forest administrations in the region typically lack technical, human, and financial resources (Pérez et al., 2005). Concession arrangements favor ex-post monitoring (Karsenty et al., 2008), which can increase the risk and transaction costs associated with felling in inappropriate areas, for example. This weeds out less-efficient operators, who in many cases are more destructive in their practices (Gbetnkom, 2005).

In this study we spatially examine the impacts that effective monitoring may have on illegal cutting in industrial forest concessions using an agent-based model of road building, tree cutting, and forest monitoring. Agent-based modeling (ABM) has been applied to a range of natural resource management issues in recent years (see BenDor et al., 2009; Berger, 2001; Berger et al., 2005; Elliston and Cao, 2006; Schlueter et al., 2009; Summers et al., 2004). In an ABM approach to modeling a system (such as agricultural, fishing, or forestry), individual resource users are modeled as 'agents'. These agents observe conditions in their environment (resources, climate, market prices, the actions of other agents, or even the consequences of their own past actions) and make decisions based on these observations, following a set of behavioral rules built into the model. Landscape-scale outcomes emerge as the consequence of the set of modeled individual decisions (e.g., deforestation patterns emerging out of individual choices about land use on farms; or fertility rates emerging out of individual decisions between work, school, and having children). The key contribution of the ABM framework to natural resource management is the ability to build links across scales between the decision processes of resource stakeholders and system-level environmental outcomes, both (1) to test how well candidate models of decisionmaking can explain observed environmental outcomes and (2) to understand what the possible consequences of observed decision-making processes may be for the future of natural 
resource systems. It is this latter application of ABM that we develop in this paper.

It is important to emphasize that the ABM framework and approach in our analysis has more an exploratory than a predictive role, because it is generally quite difficult to make precise predictions in the types of coupled natural-human systems that are typically the focus of $A B M$ approaches (Bankes, 2002). Results from single simulation runs in an ABM framework can be strongly path dependent and not predictive of the most likely outcome in the real system; however, the results observed across a large number of model runs provide a better representation of the 'possibility space' (range of possible outcomes) of environmental outcomes for the system (Brown et al., 2005). Analysis of this possibility space can provide valuable qualitative insights, rather than precise predictions, into system behavior and response. In this study we use this analytical approach to gain insight into the consequences for forests of effective monitoring of forestry operations, and to highlight key areas for empirical research on concession forestry worldwide that will help validate our understanding of the impacts of the monitoring and enforcement process.

\section{Model summary}

The model is intended to investigate the economic impacts on holders of a timber concession (the rights to cut timber in a specified area during a specified period), and environmental impacts on the land managed within the concession, of increased effort into monitoring and sanctioning operations. The model is informed by conditions in the logging industry in Cameroon, and includes three main components: (1) a forest patch, (2) a logging agent with rights to cut trees in the patch (concession) and (3) a monitoring agent, representing government or independent efforts to observe cutting infractions and levy fines.

The forest patch consists of discrete cells. Each grid cell in the forest patch has three state variables: a volume of legal timber (LT), a volume of illegal timber (IT), and a distance to nearest road, if one exists. IT can be broadly interpreted to include trees of protected species, of insufficient diameter, and trees in areas where cutting is not permitted. Timber distribution is generated by randomly placed 'hot-spots' of timber densities drawn from a power distribution, which are then kernel-smoothed to re-create the occurrence of clusters of commercially valuable species.

In the model, the holder of the logging concession and the monitor act on a forest patch representing the area allocated for cutting in a single year, assumed to be 1600 ha (Fig. A.1); there are $k$ cutting days in each year. The holder of the logging concession has a defined capacity $V_{\text {cap }}$ that can be cut from the patch, and this capacity is spread evenly across $k$ cutting days into $\mathrm{V}_{\mathrm{cap}, k}$; between cutting days the holder of the logging concession builds the necessary roads to access timber of interest. The value $V_{\text {cap }}$ is defined in the current study by the legal constraint imposed in the forest management plan (Appendix B), though it is important to note that it can also be interpreted in the model framework as a technological (capital) or labor constraint. The concession holder has initial information of the timber density in a subsample of grid cells in the forest patch (analogous to a prior survey) but also sees all grid cells within a distance of the road as cutting progresses.

The road-building strategy in this model follows FAO (1995), where the concession holder builds roads to access the densest sites of legal timber. When illegal timber is found within cutting distance from these roads, the concession holder makes a decision as to whether it will be more profitable to fill some capacity with this available illegal timber (rather than perhaps having to build more roads to meet capacity with timber that can be cut legally). This rule can be thought of as a constraint placed upon the more optimal strategy of building roads specifically to access illegal timber. As will be shown in the following sections, to the extent that the unconstrained, optimal strategy pervades in practice, we would expect the results shown in the current study (which compares the less-constrained to the more-constrained cases of ineffectively and effectively monitored forest patches) to be even stronger and more significant.

On each cutting day the monitor has the opportunity to observe cutting and administer fines. This monitoring occurs in one of two ways: (1) a random spot monitoring approach, analogous to the idea of the monitor visiting a set of randomly selected locations within the site and checking tree stumps, and (2) a checkpoint monitoring approach, analogous to a monitor waiting at a roadside checkpoint and inspecting timber loads leaving the site at the end of each cutting day.

Note that our model does not represent the processes that mediate a policy signal sent out by a governing body to enforce a regulation (Fig. 1, first arrow). Rather, the model focuses on the relationship between the mediated, perceived signal and the particular environmental goal of interest (Fig. 1, second arrow). Thus, the sanction and effort parameters can be thought of as mediated policy signals perceived by the concessionaire in which bribery and corruption are implicit. The role of governance in shaping the mediated policy signal (Fig. 1, first arrow) is an additional critical area for tropical forests research (e.g., Pedlowski et al., 2005; Soares-Filho et al., 2006), to which our model is complementary in completing the link between forest governance initiatives and measurable forest-cover outcomes.

The use of mediated policy signals allows analysis in a relatively simple model of the benefits that may accrue, and adverse consequences that may arise, through a more effectively implemented regulation. However, because we do not know the relationship between real efforts invested and mediated signal perceived (Fig. 1, first arrow), we are unable to assess the real costs of achieving forest outcomes through either monitoring approach, nor make economic comparisons between them. We note this set of relationships as important

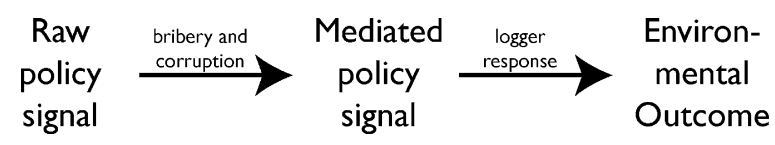

Fig. 1 - Simple linear approximation for the regulation process for natural resources like forests. The current study deals exclusively with the second part of the process, the relationship between the perceived policy signal and the environmental outcome. 

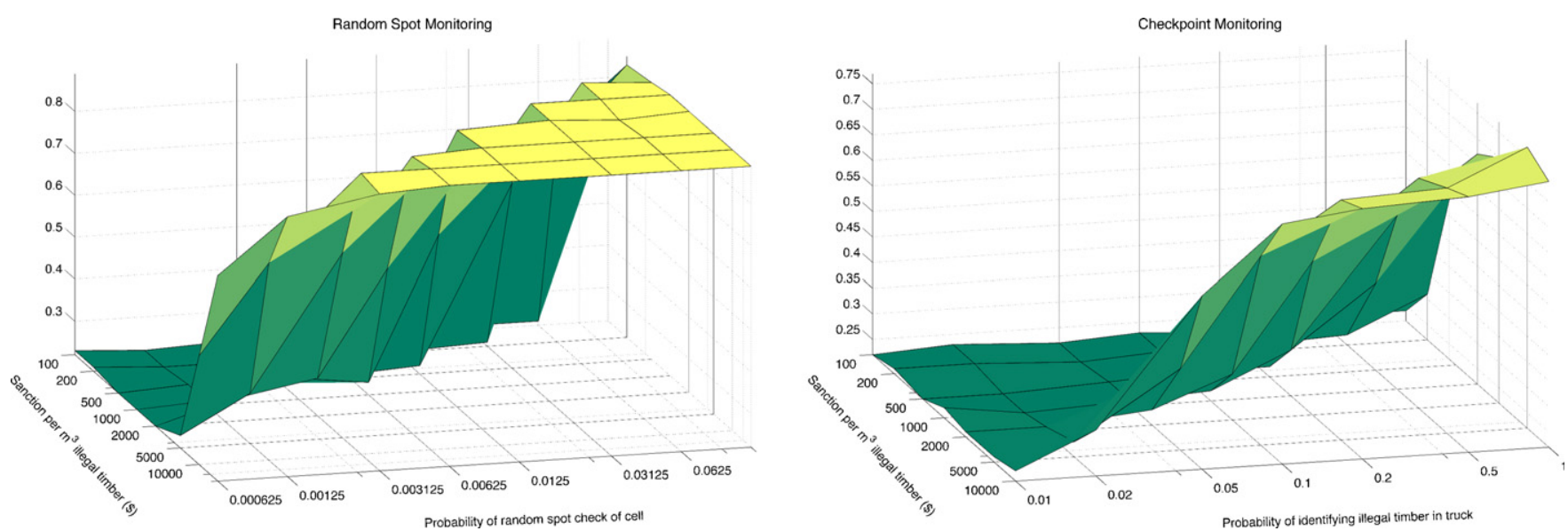

Fig. 2 - Fraction of illegal timber still standing at the end of a cutting cycle of 1 year in a forest patch, as a function of increasing sanction severity (into the page) and monitoring effort (from left to right), under spot-monitoring (left) and checkpoint monitoring (right) regimes.

areas for future research, and restrict ourselves in the following analysis to, again, investigating the relationships between net perceived policy signals and forest outcomes.

An additional but important simplification in this model is that all roads are treated equivalently - the model does not distinguish between more vs. less permanent roads in terms of their ability to provide access or their capacity to degrade and fragment. A valuable extension of the current model and its findings will be to distinguish motivations for building roads of varying degrees of permanence and link these to higherfidelity model outcomes.

A full description of the model following the ODD (Overview, Design concepts, and Details) protocol of Grimm et al. $(2006,2010)$ is included as Appendix B. Model parameters are summarized in Appendix B.

\section{Model experiments}

In the experiments described here, we focus on the effects of two key parameters of both monitoring approaches: (1) the severity of the sanction and (2) the level of effort invested in monitoring and enforcement. For both monitoring approaches, the severity of sanctions is represented by the fine levied per cubic meter of illegal timber detected. For spot monitoring, the level of effort is simply the likelihood in a given timestep of a given grid cell being randomly checked. For the checkpoint monitoring, the level of effort is represented by the maximum probability (i.e., when the truck is full of IT) of being stopped and caught at the checkpoint.

We also vary the ratio of legal timber to illegal timber, LT:IT, in the forest while maintaining constant average biomass density across experiments. This allows us to examine concessionaire decision making over the shift from a forest in which most timber present may be legally cut, to a forest in which most timber is protected and there is little available for cutting.

Finally, we vary the extent of the initial survey performed by the concessionaire, to explore the effect of information on concessionaire decisions in cutting and road building. These results are summarized in Appendix B, as our main effects are largely unaffected by changes in initial information.

Although in practice many factors may affect the substitutability of stronger sanctions for effort in monitoring, in the current simple model these two dimensions are clear substitutes, as seen by the symmetry in Fig. 2; these panels depict the changes in standing forest biomass that occur in the transition from an ineffective to an effective monitoring

\section{Table 1 Effort and fine levels represented by ordinal 'monitoring effectiveness' dimension in experiments.}

\begin{tabular}{lccccc} 
Monitoring effectiveness & \multicolumn{2}{c}{ Random spot monitoring } & & \multicolumn{2}{c}{ Checkpoint monitoring } \\
\cline { 2 - 3 } & $\begin{array}{c}\text { Harvest } \\
\text { fine }\left(\$ / \mathrm{m}^{3}\right)\end{array}$ & $\begin{array}{c}\text { Effort (probability of a given } \\
\text { grid cell being monitored) }\end{array}$ & $\begin{array}{c}\text { Harvest } \\
\text { fine }\left(\$ / \mathrm{m}^{3}\right)\end{array}$ & $\begin{array}{c}\text { Effort (probability of catching } \\
\text { a truck filled with IT) }\end{array}$ \\
\hline 1 & 0 & 0 & 0 & 0 \\
2 & 100 & 0.000625 & 200 & 0.01 \\
3 & 200 & 0.00125 & 500 & 0.02 \\
4 & 500 & 0.003125 & 1000 & 0.05 \\
5 & 1000 & 0.0625 & 2000 & 0.1 \\
7 & 2000 & 0.0125 & 5000 & 0.2 \\
8 & 5000 & 0.03125 & 10,000 & 1 \\
\hline
\end{tabular}


regime as sanctions and monitoring effort are increased. We observed the same symmetry in results for a wide range of various parameter values (not reported here). Making use of this, we collapse the two dimensions of sanction severity and

\section{Random Spot Monitoring}

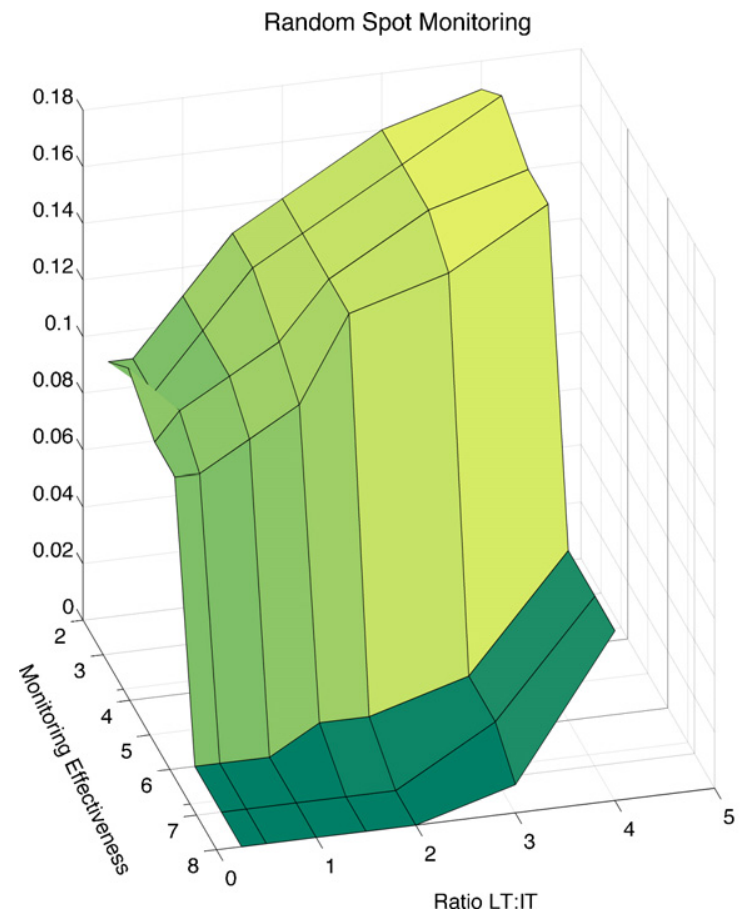

monitoring effort into a single ordinal dimension of 'monitoring effectiveness' to simplify the presentation of our analysis. The scaling of sanction severity with effort as monitoring effectiveness increases in each of the spot and checkpoint

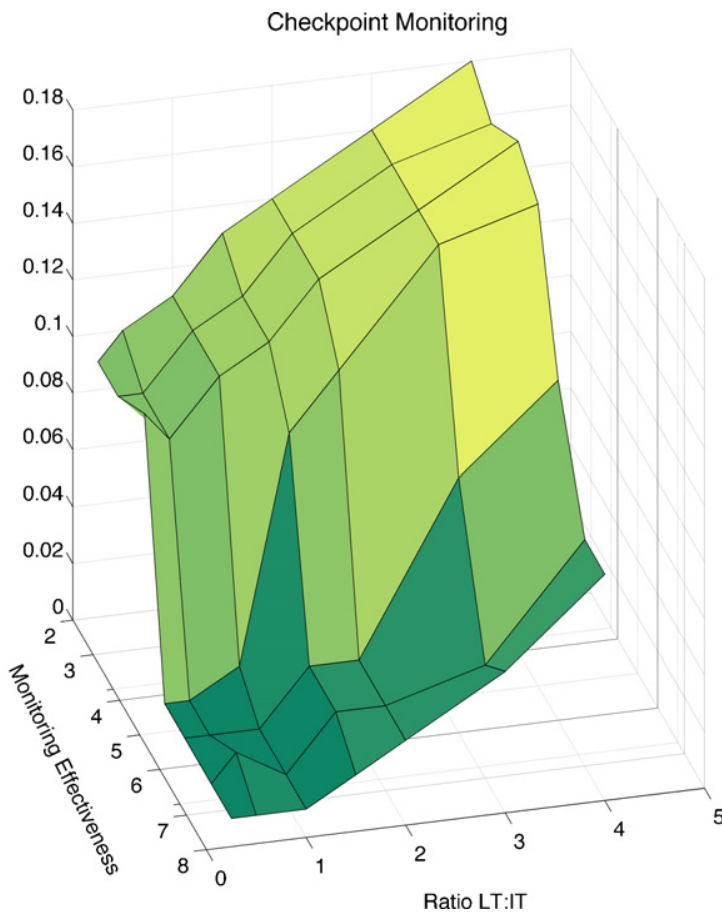

Fig. 3 - Fraction of LT left standing in a patch after one year, as a function of increasing monitoring effectiveness (coming out of the page) and increasing initial ratio of LT:IT (from left to right). Results are shown for the forest patch logged in the second year of the modeling run, after the concession-holder has estimated the risks of being caught. The response to spot monitoring is shown on the left; the response to checkpoint monitoring is shown on the right.
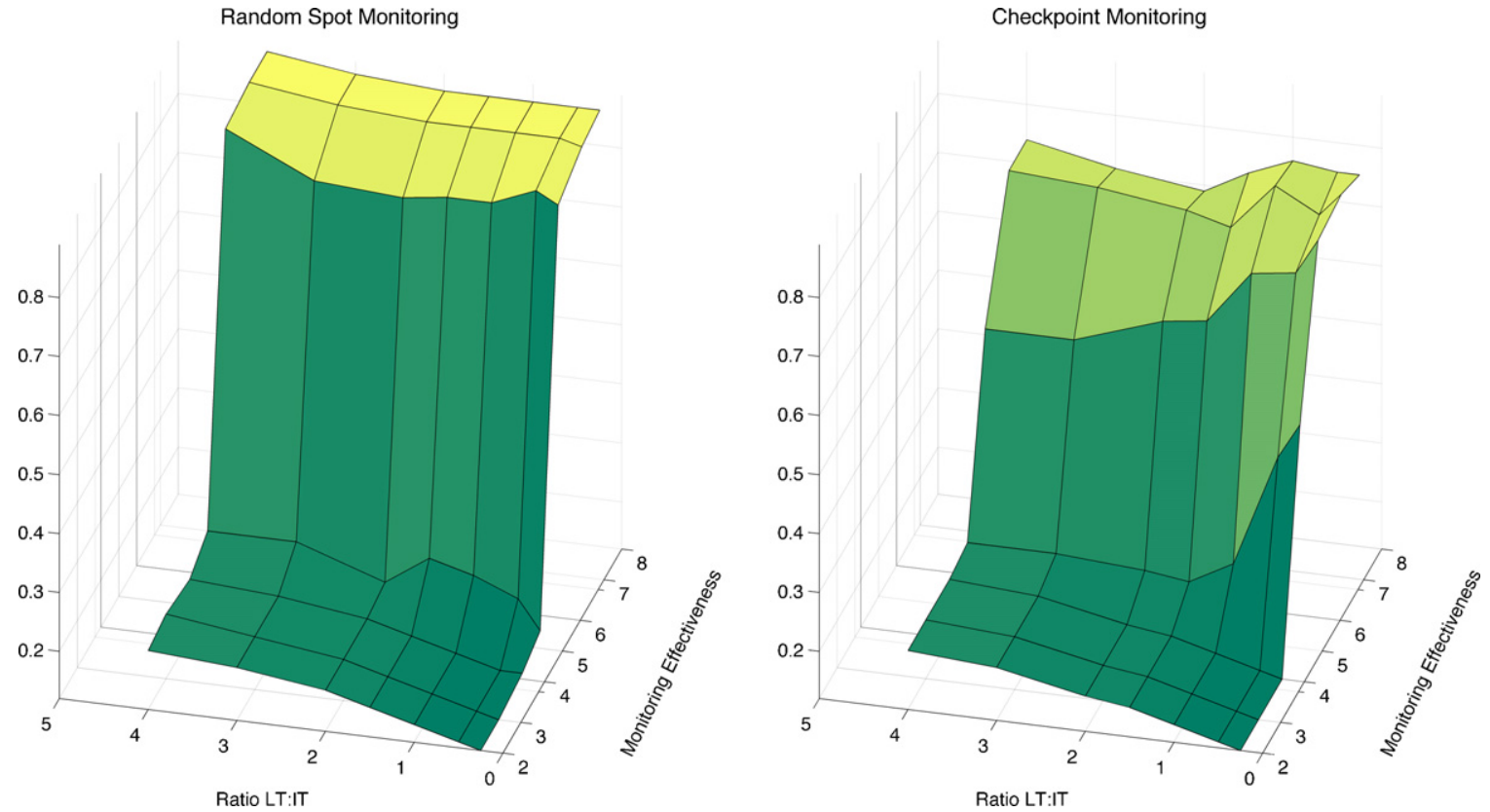

Fig. 4 - Fraction of IT left standing in a patch after one year, as a function of increasing monitoring effectiveness (going into the page) and increasing initial ratio of LT:IT (from right to left). Results are shown for the forest patch logged in the second year of the modeling run, after the concessionaire has estimated the risks of being caught. The response to spot monitoring is shown on the left; the response to checkpoint monitoring is shown on the right. 
monitoring cases is summarized in Table 1 , and can be thought of as a cut along the diagonal from the origin running between the effort dimensions (upper left to lower right in each panel of Fig. 2). This approach is also consistent with most of the economic literature on monitoring, starting with Becker (1968), which emphasizes the expected value of penalties. We have selected monitoring and sanction parameters such that the major shift away from cutting illegal timber occurs over a monitoring effectiveness range of 1-8, with much of the transition in both approaches occurring at a monitoring effectiveness of 5 or 6 . Beyond this qualitative comparison, we make no claim that a given monitoring effectiveness value means the same thing for both monitoring approaches.

In all figures in this report, each point is generated as the mean of 32 replicate model runs. Results shown are for the forest patch logged in the second year of the model run, after the concession-holder has had time to estimate costs associated with monitoring. Variance among replicates in the amount of IT preserved is greatest during the transition from a low-effectiveness to a high-effectiveness regime for the spot monitoring approach, and in the 'Sometimes cut' regime for the checkpoint monitoring approach (Fig. 2, Appendix B). Variance in the extent of road building increases with monitoring effectiveness under both monitoring approaches (Appendix B). Figs. 2-4 and 6 show statistics based on the forest cells in the grid and are comparatively smooth; Fig. 5 shows statistics based on the relatively smaller number of road nodes within the grid and is comparatively rough, while still exhibiting clear trends.

\section{Model results and discussion}

\subsection{Outcomes - standing legal and illegal timber, roads built and profits earned}

Increased monitoring effectiveness leads to more illegal timber standing at the end of the $k$ cutting days, and a greater cutting of legal timber for both monitoring approaches, lending important face validity to the functioning of the model (Figs. 3 and 4). Note that the surfaces are rotated differently for each variable to improve the views of the surfaces. In Fig. 3, monitoring effectiveness is shown as increasing coming out of the page; in Fig. 4, it increases going into the page. The ratio of LT:IT is displayed as increasing from left to right in Fig. 5, and from right to left in Fig. 4.

For the purposes of analysis we discuss three regimes of concessionaire response: the 'Always cut IT' (monitoring effectiveness of 2-5 under spot monitoring, and 2-4 under checkpoint monitoring), 'Never cut IT' (monitoring effectiveness of 6-8 under spot monitoring), and 'Sometimes cut IT' (monitoring effectiveness of 5-8 under checkpoint monitoring) regimes.

\subsection{The low regulation, 'Always cut IT' regime} (monitoring effectiveness 2-5 under spot monitoring, 2-4 under checkpoint monitoring)

When monitoring effectiveness is low, it makes economic sense for the concessionaire to cut both LT and IT in all
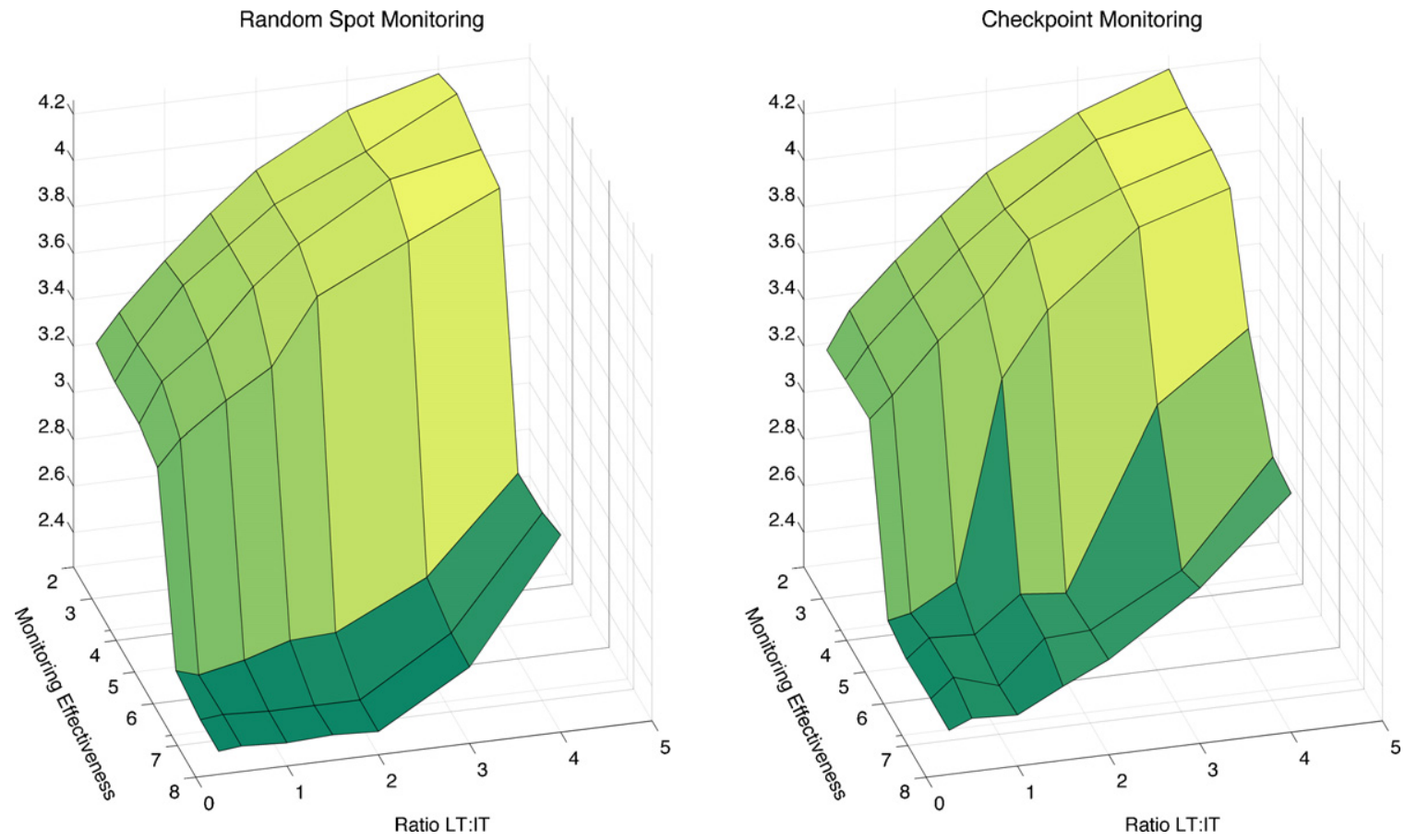

Fig. 5 - Average distance (in cells) of a given cell to a road in a patch after one year, as a function of increasing monitoring effectiveness (coming out of the page) and increasing initial ratio of LT:IT (from right to left). Results are shown for the forest patch logged in the second year of the modeling run, after the concessionaire has estimated the risks of being caught. The response to spot monitoring is shown on the left; the response to checkpoint monitoring is shown on the right. 
instances - at least $80 \%$ of both LT and IT are cut when monitoring effectiveness is less than 5 (Figs. 3 and 4). Notably in this regime, for both spot and checkpoint monitoring cases, both LT and IT decrease as the ratio of LT:IT in the forest decreases. This also corresponds with an increase in the amount of roads that are being built, increasing the number of branching points and decreasing the average distance from any given cell in the patch to a road (Figs. 5 and 6). The reason for this is that between cutting days, concessionaires build roads until they can potentially meet capacity by LT alone, even if the roads built pass through hotspots of LT and IT; it is only in the moment of cutting that they make the decision to cut IT instead of LT. Thus, as the overall proportion of LT in the forest patch decreases, roads must become longer and more branched to be able to meet capacity only by cutting LT. In building the roads in this way, the concessionaire incidentally chooses to cut more IT along the way when monitoring level is low.

This pattern in the roads is specific to the earlier-stated assumption that roads built by the concession holders will reflect only plans to cut $\mathrm{LT}$, and is a strong function of initial information when the ratio LT:IT is high. That is, the less information concession holders have when they plan where to build roads, the less they are able to target LT hotspots and the less difference the actual ratio of LT:IT makes. Furthermore, the less information they have, the less efficiently they are likely to build roads (see cases for LT:IT of 1 and 4 in Appendix B).

\subsection{Effective spot monitoring - the 'Never cut IT' regime (monitoring effectiveness 6-8)}

When monitoring effectiveness is sufficiently high in the spot monitoring case, the concessionaire cuts no IT (except when building roads), in order to avoid paying fines. In the spot monitoring case, there is a clear tipping point (around a monitoring effectiveness of 5 or 6 ) above which a large fraction of IT remains standing (Fig. 4). In this regime, IT is cut only as a side effect of roads building. Above this tipping point, effort is shifted into cutting LT, and more roads (with more branches) are built in order to reach the desired volume of LT. Within the 'Never cut' regime, similar responses to changes in the LT:IT ratio are observed as in the 'Always cut' regime - the less LT there is, the more roads get built and the more timber gets cut. The notable exception to this is that the fraction of IT standing no longer changes as LT:IT decreases. In the 'Never cut' regime, the concessionaire will avoid cutting IT whenever possible.

The threshold, tipping-point behavior occurs because (i) the concessionaire is cutting IT only when roads are already built, (ii) total cutting costs in the model are a linear function of volume, and (iii) all cells in the grid have an equal likelihood of being monitored. Thus, depending on the level of monitoring effectiveness, it either always makes economic sense to cut IT when it is close by, or never makes sense. Once the penalty is high enough, concessionaires shift their practices and do not cut IT at all (except to build roads).

\subsection{Effective checkpoint monitoring - the 'Sometimes cut IT' regime (monitoring effectiveness 5-8)}

Under checkpoint monitoring, as effectiveness increases we observe similar increases in the fraction of IT standing, but there is no 'Never cut' regime within the parameter range explored in this study. Instead, we observe a broader 'Sometimes cut' regime, across which the fraction of IT standing increases as LT:IT decreases and monitoring effectiveness
Random Spot Monitoring

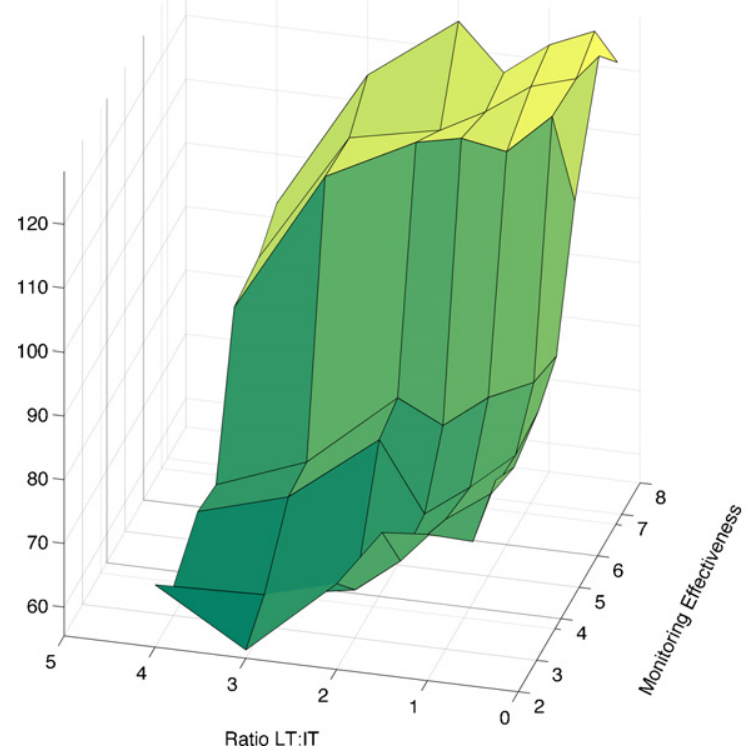

Checkpoint Monitoring

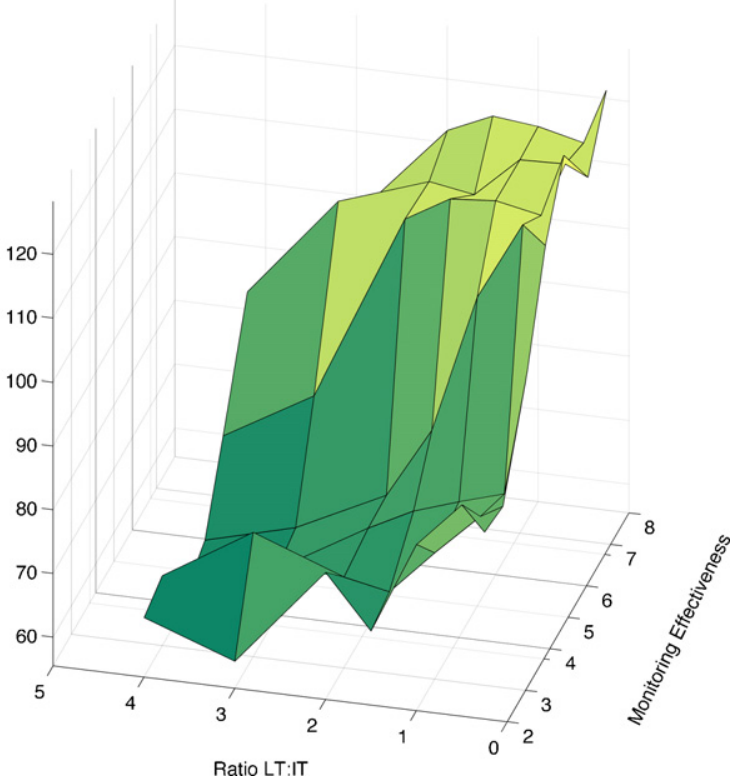

Fig. 6 - Number of road branch points (nodes) in a patch after one year, as a function of increasing monitoring effectiveness (going into the page) and increasing initial ratio of LT:IT (from right to left). Results are shown for the forest patch logged in the second year of the modeling run, after the concessionaire has estimated the risks of being caught. The response to spot monitoring is shown on the left; the response to checkpoint monitoring is shown on the right. 

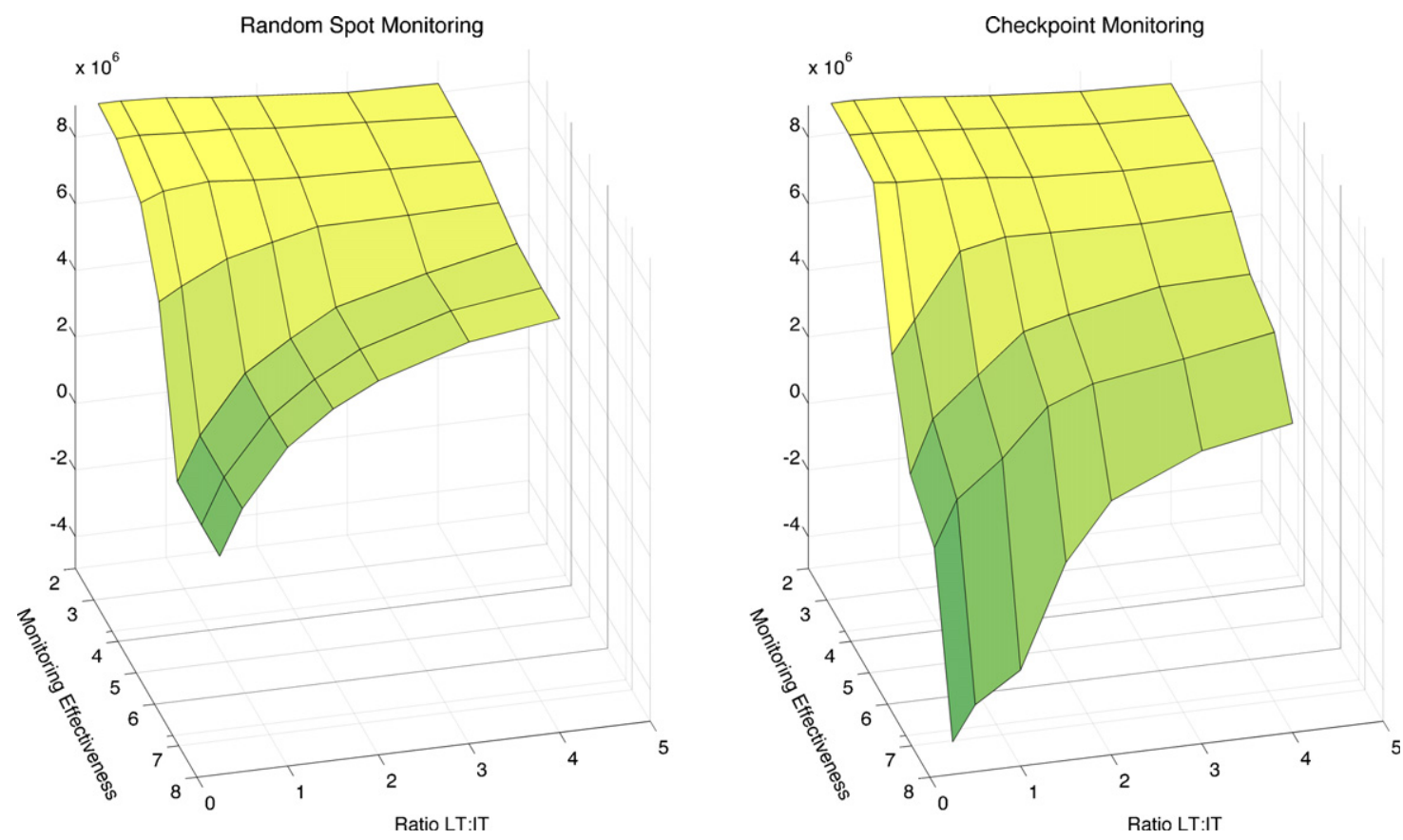

Fig. 7 - Net value (profits) derived during one year, as a function of increasing monitoring effectiveness (coming out of the page) and increasing initial ratio of LT:IT (from left to right). Results are shown for the forest patch logged in the second year of the modeling run, after the concessionaire has estimated the risks of being caught. The response to spot monitoring is shown on the left; the response to checkpoint monitoring is shown on the right.

increases (Fig. 4). Similarly, the density of roads increases with an increase in monitoring effectiveness (Figs. 5 and 6).

The reason for this more gradual transition is that the probability of getting caught depends on how much IT is loaded in the truck. Each additional unit of IT in the truck changes the probability of being caught in the same way, but with more IT in the truck, the penalty is greater. Thus, there comes a point at which the concessionaire is not willing to take any further risk of being caught (and paying fines on the stock of IT in the truck), but this point moves depending on how effective the monitoring regime is. We observe a more continuous shift toward LT and away from IT as monitoring effectiveness increases, in contrast to the sharp tipping point in the spot monitoring case (compare spot monitoring and checkpoint monitoring at monitoring effectiveness values of 5 and 6 in Figs. 3 and 4).

Across this continuous shift we are able to observe a different response to a change in the ratio LT:IT than observed in the spot monitoring case. When checkpoint monitoring is effective, the fraction of IT left standing increases as the ratio LT:IT decreases (visible most clearly in the transition region above a monitoring effectiveness of 4, Fig. 4). The simple explanation is that when there is less IT overall (when LT:IT is high), there is less IT to tempt the concessionaire and it will make up less of what is in the truck when it is cut. Further, each unit of IT cut represents a greater fraction of the total IT in the forest. As a result, the concessionaire gets caught less and leaves less of the IT remaining in the forest when LT is plentiful. As the ratio of LT:IT drops, there is more IT to cut, meaning that even as the concessionaire cuts more (and gets caught more) there remains more IT left on the ground.

\subsection{Concessionaire profitability}

The impact of monitoring and forest structure on the concessionaire's profits is easily understood. Profits rise slightly in the 'Always cut' regimes as LT:IT decreases and more timber is cut, but drop off significantly as monitoring effectiveness increases into the 'Never cut' and 'Sometimes cut' regimes; these latter drops are greater when the ratio of LT:IT is lower (Fig. 7). Profits drop significantly more for the concessionaire under checkpoint monitoring. This reflects the lower precision in the model with which the concessionaire (at the point of cutting) estimates the expected cost of illegal harvesting under checkpoint monitoring (proportional to the final load of IT at the end of the cutting day), compared with that under spot monitoring (proportional only to the value of IT to be cut at the current site).

\section{Key findings and implications}

The major result from this study is that more effective monitoring leads to greater amounts of road building and greater branching of the roads. We illustrate this above in the case of monitoring to prevent a specific type of illegal cutting (the cutting of trees that are too small or are a protected species) but the argument can be extended to other problematic practices, such as the cutting outside of allotted boundaries. In our analysis, the excessive cost associated with cutting illegal timber (IT) forced the concessionaire to build roads deeper into the allotted space to find sufficient legal timber (LT), increasing forest fragmentation. The 
restricted-area boundary problem - such as Arima et al. (2008) have observed in the Amazon case - could be represented in our model as a space occupied entirely by IT, forcing more extensive road-building into surrounding regions to meet capacity and causing similar increases in fragmentation. It is certainly true that in any context, cutting IT will occur when the net benefits of doing so compare favorably with those of moving to a new area to cut LT. However, these results highlight that as the costs of cutting IT increase, the net benefits of moving to pristine areas become more favorable, leading to higher fragmentation in the defined time periods upon which concession agreements are based. It is worth noting that the fragmentation effect emerges from the need to access more timber to meet capacity, rather than from any specific aspect of the road-building algorithm. Thus, regardless of the approach to building roads to provide access (whether a gridded 'fishbone' or an optimized, distanceminimizing solution) we would expect some degree of the same effect. As a final note on the model results, the concession holder in this model is already exhibiting a constrained behavior by planning roads based only on locations of LT. To the extent that concession holders, in practice, build roads to access IT directly (and thus are less constrained as a baseline than in this model), we would expect the shift in road building under effective monitoring to be even more significant.

The effect of denser and more branched roads on the land cover is greater forest fragmentation, which has been shown to have substantial adverse ecological consequences as shifts in light, moisture, and access allow some flora and fauna species to flourish at the expense of others (Laurance and Bierregaard, 1997; Perfecto et al., 2009; Tscharntke et al., 2007). Edge habitats become dominant and pest invasions increase with associated changes in community structure (Wilkie et al., 2000). Perhaps more important are the indirect effects on the forest brought by increased access via the roads - hunting and poaching of large game are particularly salient examples in the Congo Basin context. Wilkie et al. (1992) speculated that it was the facilitation of hunting via roads rather than tree felling that was the greater threat; Wilkie et al. (2000) found that access to roads had cut the average hunting trip in the Congo from $12 \mathrm{~h}$ to less than two. Roads also provide access for smallscale illegal logging ventures (Brown and Ekoko, 2001), whose practices may be more destructive and less efficient than those of the concession holder. Finally, though deforestation in the region is fairly low at present, demand for agricultural land is expected to increase in future, and the access provided by roads makes the resulting fragmentation a good predictor of future deforestation (Zhang et al., 2006).

A second key result is the set of qualitative differences demonstrated between the responses to spot and checkpoint monitoring approaches. In the spot monitoring case, the potential risk to the concessionaire of being caught for harvesting IT is the same at all points in the grid, at all times during the sanction period. In the checkpoint monitoring case, the risk of being caught (and the potential loss to the concessionaire) depends on what has already been cut in that time period. In the spot monitoring case it is always or never worthwhile for the concessionaire to cut IT, with a sharp threshold marking the shift between the two regimes. In contrast, in the checkpoint monitoring case it remains worthwhile (at least sometimes) to cut IT under a range of levels of monitoring effectiveness. The investment perspective for the two approaches may be then to invest in spot monitoring if there are sufficient resources to make it effective and the benefits justify the costs, and otherwise to invest in checkpoint monitoring (where there will be some level of response to even low levels of monitoring). Our analysis examines the two approaches over a comparable range of achieved forest outcomes, but does not examine the costs of achieving them. The ability to compare the cost-effectiveness of achieving particular forest outcomes through different monitoring approaches has management as well as research value, and should be a target for future research.

The insights discussed above are of particular relevance to forest governance in a REDD+ (or REDD++) world. REDD+ is a performance-based mechanism through which developedcountry donors can compensate developing countries for forest emissions reductions, including through market mechanisms (Phelps et al., 2010). To ensure that REDD+ programs and projects actually result in emissions reduction, an improved and globally acceptable system of low-cost monitoring and enforcement is crucial. Popularly referred to as MRV - monitoring, reporting, and verification - the goal of improved enforcement is to ensure that countries and agencies participating in REDD+ projects monitor these projects (either themselves or through reliable third parties), provide an estimate of the amount of additional carbon sequestered through their projects, and allow verification of their estimates by credible third parties. In essence, the effectiveness of REDD+ depends upon how much more effectively and efficiently REDD+ projects are monitored compared to past monitoring.

Our modeling analysis raises a set of questions that are empirically testable through field study and remote sensing analysis, and the current interest surrounding REDD+ and related experimentation into effective approaches at governance (e.g., Austin et al., 2010) may provide an ideal testing ground for longitudinal studies of forest management. First and most generally, are there detectable shifts in patterns of road building in response to shifts in monitoring effectiveness? Second, are there also concomitant shifts in forest ecology, and can they be attributed to observed shifts in road building or other impacts of changes in monitoring effectiveness? Third, how do these impacts vary across different approaches to monitoring? Finally, how do the costs of achieving forest outcomes compare across these different approaches? We present our analysis and the questions it raises as a point of departure for empirical scholars of landuse change and concession forestry in the tropics, and invite the coupling of existing and new data sets to models such as ours in order to improve our understanding of the links among forest ecology and forest management.

Although existing scholarship emphasizes the positive impact of effective monitoring on resource outcomes (Chhatre and Agrawal, 2008; Gibson et al., 2005; Ostrom, 1990), our research suggests that the spatial structure and specific elements of monitoring practices can have a substantial impact on how the co-benefits of REDD+ projects will be achieved. There is substantial variety in the types of 
monitoring and enforcement approaches being proposed for REDD+- our analysis suggests that some monitoring strategies may lead to greater forest fragmentation, even as they help reduce emissions. Our results indicate the value of modeling these system interactions and field testing the effects of different forest monitoring strategies to better understand how monitoring will affect not only carbon emissions, but also potential biodiversity and livelihoods outcomes generated by forests.

\section{Appendix. Supplementary data}

Supplementary data associated with this article can be found, in the online version, at doi:10.1016/j.envsci.2011. 11.005.

\section{R E F E R E N C E S}

Agrawal, A., Nepstad, D.C., Chhatre, A., 2011. Reducing emissions from deforestation and forest degradation. Annual Review of Environment and Resources 36, 373-396.

Arima, E.Y., Walker, R.T., Sales, M., Souza, C., Perz, S.G., 2008. The fragmentation of space in the Amazon basin: emergent road networks. Photogrammetric Engineering and Remote Sensing 74, 699-709.

Austin, K., Stolle, F., Elmore, S., 2010. Preparing for REDD in the Republic of Congo. World Resources Institute.

Bankes, S.C., 2002. Tools and techniques for developing policies for complex and uncertain systems. Proceedings of the National Academy of Sciences of the United States of America 99, 7263-7266.

Barrett, C., Brandon, K., Gibson, C., Gjertsen, H., 2001. Conserving tropical biodiversity amid weak institutions. Bioscience 51, 497-501.

Becker, G.S., 1968. Crime and punishment: an economic approach. Journal of Political Economy 76, 169-217.

BenDor, T., Scheffran, J., Hannon, B., 2009. Ecological and economic sustainability in fishery management: a multiagent model for understanding competition and cooperation. Ecological Economics 68, 1061-1073.

Berger, T., 2001. Agent-based spatial models applied to agriculture: a simulation tool for technology diffusion, resource use changes and policy analysis. Agricultural Economics 25, 245-260.

Berger, T., Birner, R., Diaz, J., McCarthy, N., Wittmer, H., 2005. Capturing the complexity of water uses and water users within a multi-agent framework. In: Craswell, E., Bonnell, M., Bossio, D., Demuth, S., VandeGiesen, N. (Eds.), Conference on Integrated Assessment of Water Resources and Global Change, Bonn, Germany, pp. 129-148.

Brown, D.G., Page, S.E., Riolo, R., Zellner, M., Rand, W., 2005. Path dependence and the validation of agent-based spatial models of land use. International Journal of Geographical Information Science 19, 153-174.

Brown, K., Ekoko, F., 2001. Forest encounters: synergy among agents of forest change in southern Cameroon. Society and Natural Resources 14, 269-290.

Chhatre, A., Agrawal, A., 2008. Forest commons and local enforcement. Proceedings of the National Academy of Sciences of the United States of America 105, 13286-13291.
Elliston, L., Cao, L.Y., 2006. An agent-based bioeconomic model of a fishery with input controls. Mathematical and Computer Modelling 44, 565-575.

FAO, 1995. In: FAO (Eds.), Forest Harvesting Case Study 7: Forest Harvesting in Natural Forests of the Congo. FAO, Rome, Italy.

Gbetnkom, D., 2005. Deforestation in Cameroon: immediate causes and consequences. Environment and Development Economics 10, 557-572.

Gibson, C., Williams, J., Ostrom, E., 2005. Local enforcement and better forests. World Development 33, 273-284.

Grimm, V., Berger, U., Bastiansen, F., Eliassen, S., Ginot, V., Giske, J., Goss-Custard, J., Grand, T., Heinz, S.K., Huse, G., Huth, A., Jepsen, J.U., Jørgensen, C., Mooij, W.M., Müller, B., Pe'er, G., Piou, C., Railsback, S.F., Robbins, A.M., Robbins, M.M., Rossmanith, E., Rüger, N., Strand, E., Souissi, S., Stillman, R.A., Vabø, R., Visser, U., DeAngelis, D.L., 2006. A standard protocol for describing individual-based and agentbased models. Ecological Modelling 198, 12.

Grimm, V., Berger, U., DeAngelis, D.L., Polhill, J.G., Giske, J., Railsback, S.F., 2010. The ODD protocol: a review and first update. Ecological Modelling 221, 2760-2768.

Hardin, R.R., 2011. Concessionary politics: property, patronage, and political rivalry in Central African forest management. Current Anthropology 1, 113-125.

Karsenty, A., Drigo, I.G., Piketty, M.G., Singer, B., 2008. Regulating industrial forest concessions in Central Africa and South America. Forest Ecology and Management 256, 1498-1508.

Laporte, N., Stabach, J., Grosch, R., Lin, T., Goetz, S., 2007. Expansion of Industrial Logging in Central Africa. Science 316, 1451.

Laurance, W., Bierregaard Jr., R.O., 1997. Tropical Forest Remnants: Ecology, Management, and Conservation of Fragmented Communities. University of Chicago Press, Chicago.

Mertens, B., Forni, E., Lambin, E.F., 2001. Prediction of the impact of logging activities on forest cover: a case-study in the East province of Cameroon. Journal of Environmental Management 62, 21-36.

Ostrom, E., 1990. Governing the Commons: The Political Economy of Institutions and Decisions. Cambridge University Press, Cambridge, UK.

Pedlowski, M.A., Matricardi, E.A.T., Skole, D., Cameron, S.R., Chomentowski, W., Fernandes, C., Lisboa, A., 2005. Conservation units: a new deforestation frontier in the Amazonian state of Rondonia, Brazil. Environmental Conservation 32, 149-155.

Pérez, M.R., de Blas, D.E., Nasi, R., Sayer, J.A., Karsenty, A., Sassen, M., Angoué, C., Gami, N., Ndoye, O., Ngono, G., Nguinguiri, J.C., Nzala, D., Toirambe, B., Yalibanda, Y., 2006. Socioeconomic constraints, environmental impacts and drivers of change in the Congo Basin as perceived by logging Companies. Environmental Conservation 33, 316-324.

Pérez, M.R., de Blas, D.E., Nasi, R., Sayer, J.A., Sassen, M., Angoué, C., Gami, N., Ndoye, O., Ngono, G., Nguinguiri, J.C., Nzala, D., Toirambe, B., Yalibanda, Y., 2005. Logging in the Congo Basin: a multi-country characterization of timber companies. Forest Ecology and Management 214, 221-236.

Perfecto, I., Vandermeer, J., Wright, A., 2009. Nature's Matrix. Earthscan Press, London.

Phelps, J., Webb, E., Agrawal, A., 2010. Does REDD+ threaten to recentralize forest governance? Science 328, 312-313.

Schlueter, M., Leslie, H., Levin, S., 2009. Managing water-use trade-offs in a semi-arid river delta to sustain multiple ecosystem services: a modeling approach. Ecological Research 24, 491-503.

Soares-Filho, B.S., Nepstad, D.C., Curran, L.M., Cerqueira, G.C., Garcia, R.A., Ramos, C.A., Voll, E., McDonald, A., Lefebvre, P., Schlesinger, P., 2006. Modelling conservation in the Amazon basin. Nature 440, 520-523. 
Stickler, C.M., Nepstad, D.C., Coe, M.T., McGrath, D.G., Rodrigues, H.O., Walker, W., Soares-Filho, B.S., Davidson, E.A., 2009. The potential ecological costs and cobenefits of REDD: a critical review and case study from the Amazon Region. Global Change Biology 2803-2824.

Summers, P.M., Browder, J.O., Pedlowski, M.A., 2004. Tropical forest management and silvicultural practices by small farmers in the Brazilian Amazon: recent farm-level evidence from Rondonia. Forest Ecology and Management 192, 161-177.

Tscharntke, T., Leuschner, C., Zeller, M., Guhardja, E., Bidin, A., 2007. The Stability of Tropical Rainforest Margins, Linking
Ecological, Economic and Social Constraints of Land Use and Conservation. Springer Verlag, Berlin.

Wilkie, D., Shaw, E., Rotberg, F., Morelli, G., Auzel, P., 2000. Roads, development, and conservation in the Congo Basin. Conservation Biology 14, 1614-1622.

Wilkie, D., Sidle, J.G., Boundzanga, G.C., 1992. Mechanized logging, market hunting, and a bank loan in Congo. Conservation Biology 6, 570-580.

Zhang, Q., Justice, C.O., Jiang, M., Brunner, J., Wilkie, D., 2006. A GIS-based assessment on the vulnerability and future extent of the tropical forests of the Congo Basin. Environmental Monitoring and Assessment 2006, 107-121. 